\title{
Innovation in Teaching Mode of Higher Education Under the Background of Made in China 2025
}

\author{
Datong Cui ${ }^{\mathrm{a}}$, Hongtao $\mathrm{Yu}^{\mathrm{b}}{ }^{*}$, Yan Bao ${ }^{\mathrm{c}}$ and Zijian Zhang ${ }^{\mathrm{d}}$
}

\author{
College of Automation, Shenyang Institute of Engineering, Shenyang Liaoning110136, China \\ accuidatong9558@sohu.com, 'bneu970773@sohu.com, 'dianzixinxi2004@163.com, \\ d384495501@qq.com
}

Keywords: Control system; Simulation; Simulink; Made in China 2025

\begin{abstract}
The key to the implementation of the "Made in China 2025" strategic plan is to adapt the upgraded version of the labor structure. The teaching mode of higher education must be innovated in this context. Matlab is a computer language development software produced by foreign MathemWork company. It is used in computer language system and exchange environment. It is mainly used for algorithm development, data visualization, data analysis and numerical operation. When a user needs to solve the problem of a professional subject, ToolBox, as a powerful analytical solution tool, has a powerful computing function and a graphical representation of Matlab, which will be widely applied to some special mathematical tool functions or pins for such complex and complicated numeric and programming, ToolBox in Matlab It plays a great role.
\end{abstract}

\section{Introduction}

Teaching mode[1,2] of higher education must be changed under the backgound of Made in China 2025[3-5]. Matlab[6-8] has many functions in advanced mathematics, statistics, and engineering functions, and computer users can instantly realize the powerful mathematical computing functions needed. The advanced algorithm, which is mainly used for safety and reliability, ensures the maximization of processing speed and optimal results. It is more convenient and fast. Most of the computational mathematical function library modules are stored in the current Matlab software version. Most of the operational modules involved in Higher Mathematics involve many complex system functions. For example, matrix processing in algebra, matrix eigenvalue and matrix equation inversion The functions of the calculation, the function Fu Liye transform and so on. The basic unit of Matlab's processing data is the matrix. At the same time, Matlab also absorbs the advantages of Maple and other software, making Matlab more convenient than other language software. The design and Simulation of the control system in the simulation environment of Matlab is very efficient and highly accurate. In this environment, it combines the advantages of fast analysis and processing of numerical values, engineering scientific data, visual calculation matrix values, modeling of discrete and continuous systems, simulation and other multi-functional advantages. In a simple application window environment, a comprehensive and efficient solution is provided for scientific and technological research and system engineering design. To a certain extent, it is free from the editing domain of the traditional system non commutative programming language. From the characteristic curve of the simulation, it can be seen that by adjusting the system parameters by the computer users, the system is finally stable within the initial set value, and the steady-state error is in the standard model.

\section{The Functional Characteristics of Matlab}

Matlab in Control Scientific Engineering. The principle of Matlab works with arrays as a computing unit, and the problem of computing related data is most beneficial to advanced algorithms and advanced technologies in Matlab. In other words, it has the advantages of high operation and good stability. Not only can the basic calculation be handled, but the Matlab software can be used to solve the numerical problems of many specific types of functions in the field of mathematics, which are relative to the 
complex systems, such as the rigid system and the efficient and accurate Bessel function, to support multiple bit values, and the solution of the coefficient matrix. Eigenvalues and singular values.

Design Language. It not only has the powerful function of the highly hierarchical programming language, but also has the advantage that it has more functional modules than any advanced language system in control debugging technology, and Matlab can automatically set clear breakpoints for the system. The basic data element of Matlab programming language is vector matrix. Considering the programming of control objects and basic mathematical problems, it satisfies the solution of simple mathematical problems and the input and output of a variety of functional data structures. It is also applicable, for example, to develop a large program that corresponds to a complex control system. When designing a program, an array element, an array or a multi line type, the array variable can be used as a whole access system. Matlab also has a convenient and flexible multi intelligence computing device. This type of module makes the application field of Matlab larger.

Matlab Text Processing Function. At the main interface, computer users can edit and execute instructions, calculate and execute instructions in time, and their instructions are "Live" commands. Another way is to type the Live instruction at the program interface and run in this way, and it runs in this way for the Matlab main window interface. Now, the main function of Matlab is to face most practical control engineering applications. When the system interface function library calls the subroutines of Matlab, it is not only a number of methods to call subroutines, and the user can also use the language $\mathrm{C}$ and $\mathrm{C}++$ to operate the above steps. It can be summed up in two ways: first, real-time dynamic linking external $\mathrm{C}$ or enabling Fortran application functions. Another way: using the Matlab function in an independent $\mathrm{C}$ or Fortran program, and entering a data file of various Matlab design programs and standard format properties at the program compilation interface.

\section{Simulation and Application Example of Matlab}

The Simulation Function of Matlab. As one of the core components of Matlab, the Simulink module $[9,10]$, from its main function, creates a dynamic system modeling, integrated numerical analysis, and simulation integrated environment. Because it works under the Windows interface, there is no need to write large numbers of programs, so that the editing interface and the block diagram of the control system are very convenient.

An example of Matlab frequency analysis:

The open-loop transfer function of the system is to draw its Bode diagram, Nyquist diagram and Nichols diagram through simulation program.

The following procedures are as follows:

Bode drawing:

$>$ num $=\left[\begin{array}{ll}0.3 & 1\end{array}\right]$

num $=$

$0.3000 \quad 1.0000$

$\gg$ den $=\left[\begin{array}{lll}1 & 0.5 & 0\end{array}\right]$

den $=$

$1.0000 \quad 0.5000 \quad 0$

> $\mathrm{G}=\mathrm{tf}$ (num,den)

Transfer function:

$0.3 \mathrm{~s}+1$

$\mathrm{s} 2+0.5 \mathrm{~s}$

$>$ bode $(\mathrm{G})$

grid

>>Bode

The result is shown in Fig. 1. 


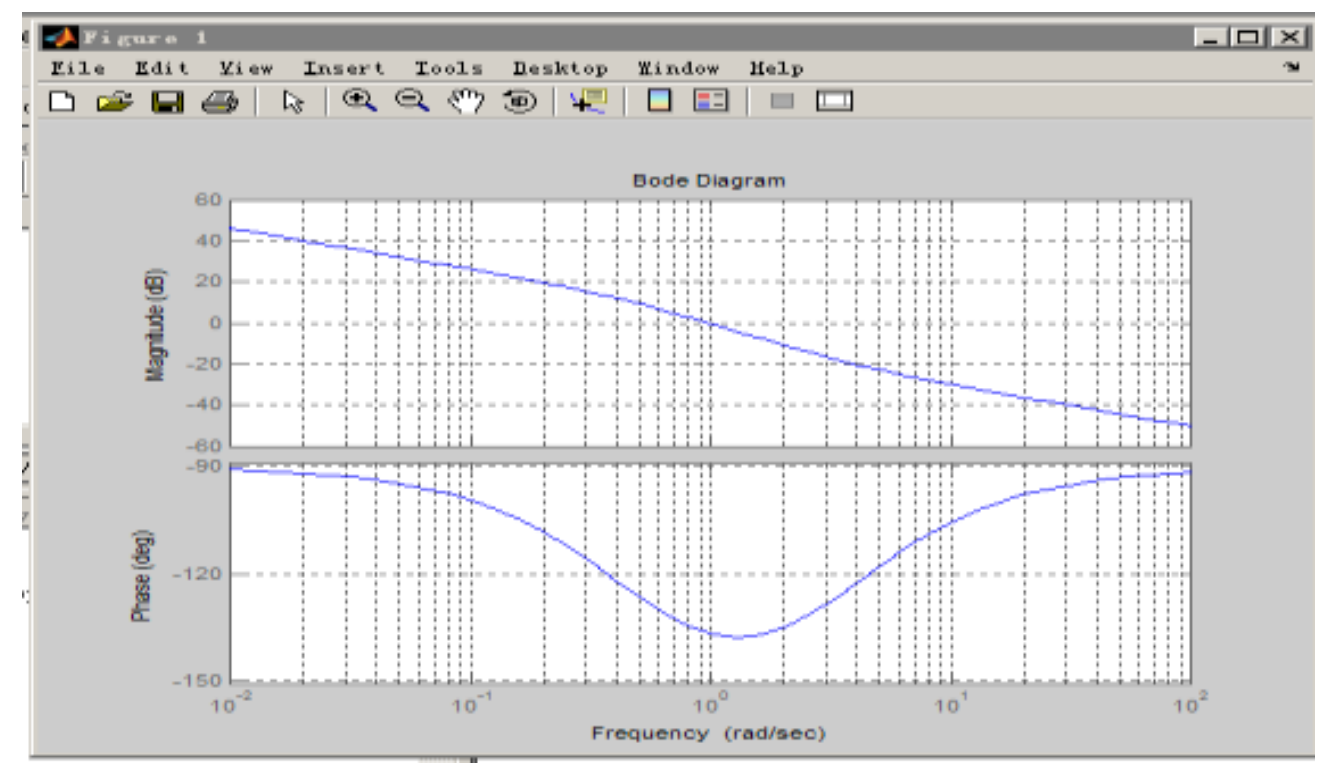

Figure 1. The curve of Bode graph

Application Example of Simulink Module. The modules are connected according to the mathematical model, the results are shown in Fig. 2. and Fig. 3.

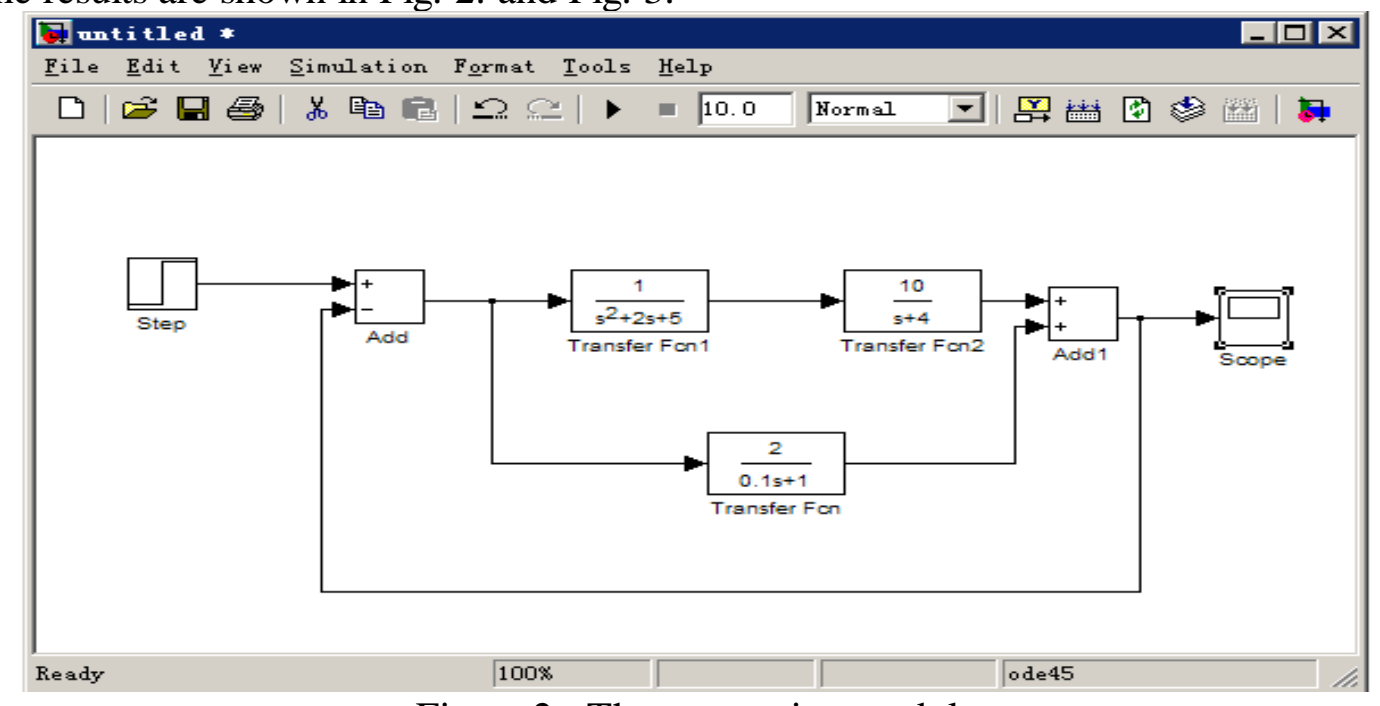

Figure 2. The connection module

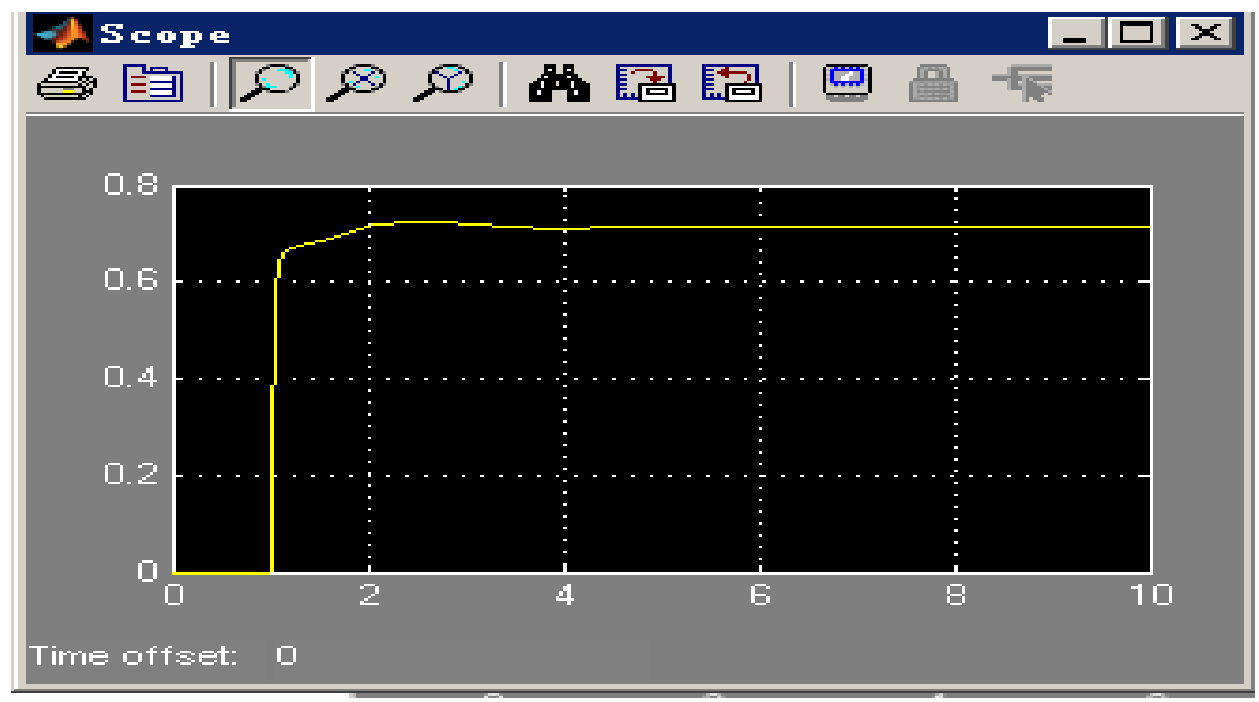

Figure 3. The simulation results 


\section{Summary}

In order to train men for profession under the backgound of Made in China 2025, this paper takes the Matlab course as an example to reform the teaching mode. Firstly, for the Simulink simulation environment, the main purpose of the design system is to be analyzed, and the simulation module can be selected to analyze the system accurately. Secondly, the connection of each link between the system should be taken into account, and the module is formed. The operation of drawing by Matlab, the design steps and simulation process are given in the paper.

\section{Acknowledgements}

This work was supported in part by Liaoning Province Education Science " The 13th Five-Year Plan" project under Grant No. JG17DB354, JG17DB343, JG17DB355 and JG16DB523 and the educational reform project of the Liaoning provincial education department in 2016 under Grant 637 and 638.

\section{References}

[1] Zeng N, Liu J. An Empirical Study on Task-based Listening Teaching Mode in Junior High School of China[J]. Advances in Language \& Literary Studies, 2017, 8(2):202.

[2] Wang L. Exploring the Convergence of the Mobile Learning Mode in Network Environment and the Traditional Classroom Teaching Mode[J]. International Journal of Emerging Technologies in Learning, 2017, 12(7):170.

[3] Liu S X. Innovation Design: Made in China 2025[J]. Design Management Review , 2016 , 27 (1) :52-58.

[4] Wu H, Benson S A. Made In China 2025 and New Trends of Entrepreneurship Education of China: A Socio-Economic-Educational Perspective[J]. 2016, 2(1):10.

[5] Chen J L. The Cases Study of “One Belt and One Road" and "Made in China 2025" Impact on the Development of Taiwan's Machine Tool Industry[J]. International Business Research, 2018, 11(2):189.

[6] Whitty M. Robotics, Vision and Control. Fundamental Algorithms in MATLAB[J]. Industrial Robot, 2017, 39(6):75-85.

[7] Gibaldi A, Vanegas M, Bex P J, et al. Evaluation of the Tobii EyeX Eye tracking controller and Matlab toolkit for research[J]. Behavior Research Methods, 2017, 49(3):923-946.

[8] Yue D, Li M Y, Tong Q, et al. Edge detection and mathematic fitting for corneal surface with Matlab software[J]. International Journal of Ophthalmology, 2017, 10(3):336-342.

[9] Liu B, Nejati S, Briand L C, et al. Simulink fault localization: an iterative statistical debugging approach[J]. Software Testing Verification \& Reliability, 2016, 26(6):431-459.

[10] Schmidt A, Durak U, Pawletta T. Model-based testing methodology using system entity structures for MATLAB/Simulink models[J]. Simulation, 2016, 92(8):729-746. 